\title{
Effect of ionic liquids on kinetic parameters of dicyanate ester polycyclotrimerization and on thermal and viscoelastic properties of resulting cyanate ester resins
}

\author{
A. Fainleib ${ }^{1}$, O. Grigoryeva ${ }^{1}$, A. Vashchuk ${ }^{1,3}$, O. Starostenko ${ }^{1}$, S. Rogalsky ${ }^{2}$, A. Rios de Anda ${ }^{3}$, \\ T-T-T. Nguyen ${ }^{3}$, D. Grande ${ }^{3 *}$ \\ ${ }^{1}$ Institute of Macromolecular Chemistry, National Academy of Sciences of Ukraine, Kharkivske shose 48, 02160 Kyiv, \\ Ukraine \\ ${ }^{2}$ Institute of Bioorganic Chemistry and Petrochemistry, National Academy of Sciences of Ukraine, Kharkivske shose 50, \\ 02160 Kyiv, Ukraine \\ ${ }^{3}$ Institut de Chimie et des Matériaux Paris-Est, UMR 7182 CNRS - Université Paris-Est Créteil Val-de-Marne, 2, rue \\ Henri Dunant, 94320 Thiais, France
}

Received 6 November 2018; accepted in revised form 4 January 2019

\begin{abstract}
A strong catalytic effect of $1.0 \mathrm{wt} \%$ ionic liquids (ILs) on kinetic parameters of dicyanate ester of bisphenol $\mathrm{E}$ (DCBE) polycyclotrimerization was evidenced, and structure-property relationships of resulting densely cross-linked cyanate ester resins (CERs) were investigated. Three different ILs with contrasted reactivity were employed as a catalysts: an aprotic IL, i.e. 1-octyl-3-methyl imidazolium tetrafluoroborate ([OMIm] $\left.\left[\mathrm{BF}_{4}\right]\right)$, a protic IL, i.e. 2-(hydroxyethylamino) imidazolinium chloride ([HEAIm][Cl]), and a protic polymeric IL, i.e. poly(hexamethylene guanidine) toluene sulfonate ([PHMG][TS]). Both $[\mathrm{HEAIm}][\mathrm{Cl}]$ and $[\mathrm{PHMG}][\mathrm{TS}]$ were reactive towards DCBE monomer, whereas $[\mathrm{OMIm}]\left[\mathrm{BF}_{4}\right]$ was chemically inert, as confirmed by Fourier Transform Infrared (FTIR) spectroscopy. Noticeably, the conversion $\left(\alpha_{c}\right)$ of cyanate groups in the presence of ILs dramatically increased, and a significant dependence of $\alpha_{c}$ values on IL chemical structure was found. The corresponding mechanisms of DCBE polycyclotrimerization in the presence of different ILs were proposed. All the CER/IL networks exhibited a high thermal stability inherent to neat CER, as shown by TGA, whereas unexpected significant changes of the viscoelastic characteristics for CER/IL networks compared to pure CER analogue were observed using DMTA.
\end{abstract}

Keywords: thermosetting resins, ionic liquids, catalytic effect, thermal stability, viscoelastic properties

\section{Introduction}

Cyanate ester resins (CERs) represent a family of thermosetting polymers possessing attractive intrinsic features, such as excellent dimensional stability, high glass transition temperature $\left(T_{\mathrm{g}}>250^{\circ} \mathrm{C}\right)$, low dielectric constants (2.5-3.2), flame-retardancy, and high adhesion to conductor metals and composites. Therefore, they are promising materials for aerospace and microelectronic applications, especially as polymer matrices for structural composites, adhesives, potting resins, and coatings that work under severe conditions (high temperature, humidity, corrosive media, etc) [1-6]. Dicyanate ester monomers undergo thermal polycyclotrimerization to generate high $T_{\mathrm{g}}$ polycyanurate networks ( $\mathrm{PCNs}$ ), i.e. cyanate ester resins (CERs), without releasing volatile products. Figure 1 describes the reaction scheme of polycyclotrimerization of one of the widely used monomers, i.e. dicyanate ester of bisphenol $\mathrm{E}$ (DCBE).

Dicyanate ester homopolymerization occurs at high temperature in the presence or the absence of a specific catalyst. The rate of non-catalyzed polycyclo- 


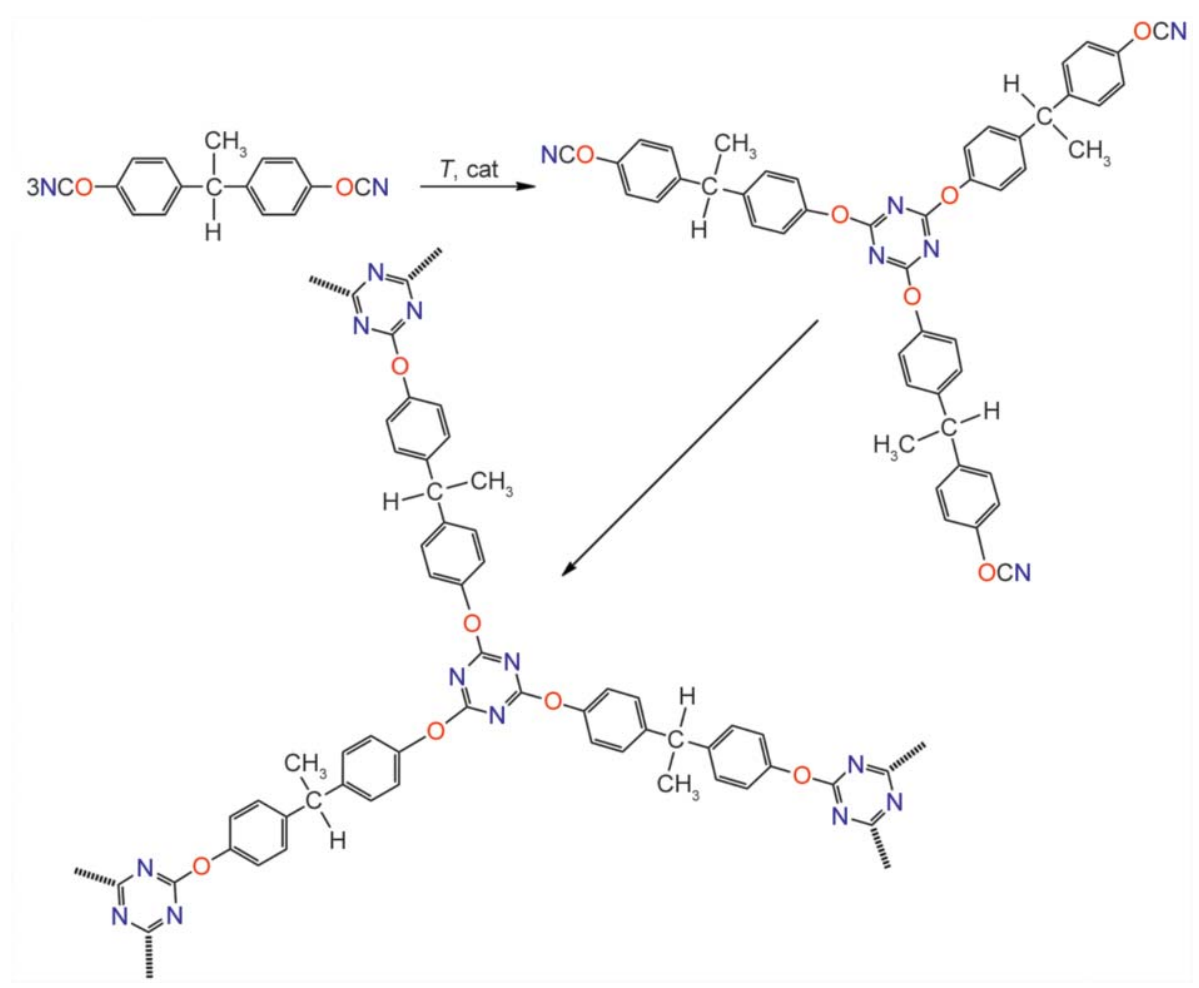

Figure 1. Reaction scheme of DCBE polycyclotrimerization.

trimerization is generally slow, and it depends on the concentration of impurities (traces of phenols and other residues from synthesis) [1]. Using a catalyst is necessary to achieve a controlled polycyclotrimerization process, which is a key factor for producing materials with excellent properties. This reaction is generally catalyzed by a combination of salts of transition metals, like acetyl acetonates of $\mathrm{Cu}, \mathrm{Co}, \mathrm{Zn}, \mathrm{Fe}$, $\mathrm{Mn}, \mathrm{Cr}$, etc. and an active hydrogen containing initiator like nonylphenol. Because of the well-known toxicity of phenolic compounds, attempts to find new effective catalysts for dicyanate ester polycyclotrimerization are of scientific and practical interest. In this regard, Throckmorton and Palmese [7] have found an acceleration of cyanate ester trimerization by dicyanamide-containing ionic liquids (ILs).

ILs are salts with melting points at temperatures below $100^{\circ} \mathrm{C}$. They have attracted much attention due to their interesting properties, including negligible vapour pressure, large choice of salts liquid at room temperature, tunable physico-chemical characteristics, excellent thermal and chemical stability, selective solubility, ease of synthesis and good stability to oxidative and reductive conditions [8]. Since they are nonflammable, non-volatile and recyclable, they are greener alternatives to conventional organic solvents. Furthermore, they may be used as effective and reusable catalysts in some polymerization reactions [9-13] and as initiators of free-radical [14, 15] or cationic $[16,17]$ polymerization processes. Thus, ILs have attracted widespread interest in polymer chemistry, due to their versatile properties $[18,19]$. In addition, ILs can also be suitable as porogens for producing nanoporous films and membranes, due to their high thermal stability and chemical inertness. In this regard, our teams have indeed successfully used 1-heptyl pyridinium tetrafluoroborate $[\mathrm{HPyr}]\left[\mathrm{BF}_{4}\right]$ as inert porogenic agent to produce nanoporous thermostable CER films [20].

Recently, our consortium has also found that an addition as small as $1.0 \mathrm{wt} \%$ of the latter aprotic IL significantly accelerated the kinetics of DCBE polycyclotrimerization, which was explained by the formation of a $[\mathrm{CN}]^{\delta+}[\mathrm{HPyr}]^{\delta-}$ complex as a key intermediate [21].

In the present paper, we thoroughly investigate the catalytic behaviour of three ILs with contrasted reactivity, namely an aprotic IL, i.e. $[\mathrm{OMIm}]\left[\mathrm{BF}_{4}\right]$, a protic IL, i.e. 2-(hydroxyethylamino) imidazolinium chloride ([HEAIm] $[\mathrm{Cl}])$, and a protic polymeric IL, i.e. poly(hexamethylene guanidine) toluene sulfonate ([PHMG][TS]). For the first time, a comprehensive investigation of their effect on kinetic parameters (induction time, reaction time, monomer conversion 
degree, etc.) of DCBE polycyclotrimerization as well as on thermal stability and viscoelastic properties of the resulting CERs is addressed.

\section{Experimental}

\subsection{Materials}

1,1-bis(4-cyanatophenyl) ethane (dicyanate ester of bisphenol E, DCBE), under the trade name PRI-

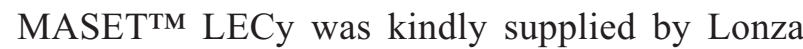
(Switzerland), and was used as received. The following chemicals (Fluka) were used as received for the synthesis of ILs: 1-methylimidazole, 1-bromooctane, 2-ethanolamine, tetrafluoroboric acid $\left(50 \%\right.$ in $\left.\mathrm{H}_{2} \mathrm{O}\right)$, ethyl acetate, hexane, methylene chloride, sodium sulfate, isopropanol, potassium hydroxide, guanidine hydrochloride, hexamethylenediamine, $0.1 \mathrm{~N}$ sodium chloride, sodium toluenesulfonate, and ethanol.

\subsection{Synthesis of ionic liquids}

\subsubsection{Synthesis of 1-octyl-3-methyl imidazolium tetrafluoroborate ([OMIm] $\left[\mathrm{BF}_{4}\right]$ )}

$[\mathrm{OMIm}]\left[\mathrm{BF}_{4}\right]$ ionic liquid was synthesized using literature methods previously described $[22,23]$. The stirred mixture of 1-bromooctane $(27 \mathrm{~g}, 0.14 \mathrm{~mol})$ and 1-methylimidazole (10 g, $0.12 \mathrm{~mol})$ was heated at $140^{\circ} \mathrm{C}$ for $2 \mathrm{~h}$ under argon atmosphere. The viscous liquid of light brown color obtained was cooled to room temperature and washed with ethyl acetatehexane mixture $(3: 1(\mathrm{v} / \mathrm{v}), 3 \times 100 \mathrm{ml})$. Residual solvents were removed at reduced pressure and the obtained product was dissolved in $150 \mathrm{ml}$ of water. Tetrafluoroboric acid $(25 \mathrm{ml})$ was added to the solution followed by stirring for $1 \mathrm{~h}$. The immiscible aqueous layer formed was extracted with methylene chloride $(2 \times 100 \mathrm{ml})$, and dried overnight with sodium sulfate. The solvent was distilled off, and the resulting ionic liquid was dried under reduced pressure of $1 \mathrm{mbar}$ at $80^{\circ} \mathrm{C}$ for $12 \mathrm{~h}$. The product yield was equal to $72 \%$. ${ }^{1} \mathrm{H}$ NMR (300 MHz, $\mathrm{CDCl}_{3}$ ): $\delta[\mathrm{ppm}]: 0.86(\mathrm{t}, 3 \mathrm{H}$, $\left.\mathrm{CH}_{3}, J=7.2 \mathrm{~Hz}\right), 1.25-1.31\left(\mathrm{~m}, 9 \mathrm{H}, \mathrm{CH}_{2}\right), 1.86(\mathrm{~m}$, $\left.3 \mathrm{H}, \mathrm{CH}_{2}\right), 3.94$ (s, $\left.3 \mathrm{H}, \mathrm{NCH}_{3}\right), 4.16$ (t, $2 \mathrm{H}, \mathrm{NCH}_{2}$, $J=7.2 \mathrm{~Hz}), 7.27-7.38(\mathrm{~m}, 2 \mathrm{H}, \mathrm{NC}(\mathrm{H}) \mathrm{C}(\mathrm{H}) \mathrm{N}), 8.78$ (s, $1 \mathrm{H}, \mathrm{NC}(\mathrm{H}) \mathrm{N})$.

${ }^{19} \mathrm{~F} \mathrm{NMR}\left(188 \mathrm{MHz}, \mathrm{CDCl}_{3}\right): \delta[\mathrm{ppm}]:-151.4$. ${ }^{1} \mathrm{H}$ NMR (300 MHz, DMSO- $\left.d_{6}, \mathrm{TMS}\right): \delta[\mathrm{ppm}]$ : $0.85\left(\mathrm{t}, 3 \mathrm{H}, \mathrm{CH}_{3}\right), 1.25\left(\mathrm{~m}, 10 \mathrm{H}, \mathrm{CH}_{3}\left(\mathrm{CH}_{2}\right)_{5}\right), 1.78$ $\left(\mathrm{m}, 2 \mathrm{H}, \mathrm{NCH}_{2} \mathrm{CH}_{2}\right), 3.85\left(\mathrm{~s}, 3 \mathrm{H}, \mathrm{NCH}_{3}\right), 4.16(\mathrm{t}, 2 \mathrm{H}$, $\mathrm{NCH}_{2}$ ), 7.67 (br s, $\left.1 \mathrm{H}, \mathrm{C}_{4}-\mathrm{H}\right), 7.74$ (br s, $1 \mathrm{H}, \mathrm{C}_{5}-\mathrm{H}$ ), $9.06\left(\mathrm{~s}, 1 \mathrm{H}, \mathrm{C}_{2}-\mathrm{H}\right)$.
${ }^{19} \mathrm{~F}$ NMR $\left(188 \mathrm{MHz}, \mathrm{DMSO}-d_{6}, \mathrm{CFCl}_{3}\right): \delta[\mathrm{ppm}]:$ $-148.8\left(\mathrm{~s}, 4 \mathrm{~F}, \mathrm{BF}_{4}\right)$.

\subsubsection{Synthesis of 2-(hydroxyethylamino) imidazolinium chloride ([HEAIm] [Cl])}

2-methylmercaptoimidazoline-2-chlorohydrate was obtained according to a literature method [24].

${ }^{1} \mathrm{H}$ NMR (300 MHz, DMSO- $\left.d_{6}\right): \delta[\mathrm{ppm}]: 2.71$ (s, 3H, $\left.\mathrm{CH}_{3}\right), 3.84$ (s, 4H, $\left.\mathrm{CH}_{2}\right), 10.64$ (2H, br s, NH).

The stirred mixture of 2-methylmercaptoimidazoline-2-chlorohydrate $(5 \mathrm{~g}, 0.032 \mathrm{~mol})$ and 2-ethanolamine $(2.1 \mathrm{~g}, 0.035 \mathrm{~mol})$ in $50 \mathrm{ml}$ of isopropanol was heated to boiling for $6 \mathrm{~h}$. Methylmercaptane formed as by-product was absorbed by $20 \%$ water solution of potassium hydroxide. The solvent was removed at reduced pressure and the obtained solid residue of [HEAIm $][\mathrm{Cl}]$ was purified by double recrystallization from isopropanol. Yield: $85 \%$.

${ }^{1} \mathrm{H}$ NMR (300 MHz, DMSO- $\left.d_{6}\right): \delta[\mathrm{ppm}]: 3.25$ (m, $\left.2 \mathrm{H}, \mathrm{CH}_{2} \mathrm{OH}\right), 3.56\left(\mathrm{~m}, 6 \mathrm{H}, \mathrm{NHCH}_{2} \mathrm{CH}_{2} \mathrm{OH}\right), 7.64$ $(4 \mathrm{H}$, br s, NH, OH).

\subsubsection{Synthesis of poly(hexamethylene guanidine) toluene sulfonate ([PHMG][TS])}

The mixture of guanidine hydrochloride $(10 \mathrm{~g}$, $0.104 \mathrm{~mol})$ and hexamethylene diamine $(11.7 \mathrm{~g}$, $0.1 \mathrm{~mol}$ ) was heated at $100^{\circ} \mathrm{C}$ for $4 \mathrm{~h}$ under constant stirring. Further, the reaction was carried out for $4 \mathrm{~h}$ at $140{ }^{\circ} \mathrm{C}, 4 \mathrm{~h}$ at $180^{\circ} \mathrm{C}$ and $3 \mathrm{~h}$ at $200^{\circ} \mathrm{C}$ to obtain a highly viscous liquid. After cooling the reaction mixture to room temperature, the vitreous solid of poly (hexamethylene guanidine) hydrochloride obtained ([PHMG] $] \mathrm{Cl}])$ was dissolved in water $(150 \mathrm{ml})$, filtered and precipitated by addition of saturated water solution of sodium chloride $(50 \mathrm{ml})$. The polymer was isolated by decantation of water solution, dried at $140{ }^{\circ} \mathrm{C}$ for $24 \mathrm{~h}$ and ground in a porcelain mortar. The intrinsic viscosity was equal to $7 \mathrm{~cm}^{3} / \mathrm{g}$ for $[\mathrm{PHMG}][\mathrm{Cl}]$ solution in $0.1 \mathrm{M}$ sodium chloride at $25^{\circ} \mathrm{C}$

${ }^{1} \mathrm{H}$ NMR (300 MHz, DMSO- $\left.d_{6}\right): \delta$ [ppm]: $1.3-1.44$ (m, 8H, $\left.\left(\mathrm{CH}_{2}\right)_{4},\right), 3.14\left(\mathrm{~m}, 4 \mathrm{H},\left(\mathrm{N}-\mathrm{CH}_{2}\right)_{2}\right), 7.15-7.8$ (br s, 4H, C-NH, C= $\mathrm{NH}_{2}{ }^{+}$).

Elemental analysis: $\left(\mathrm{C}_{7} \mathrm{H}_{16} \mathrm{~N}_{3} \mathrm{Cl}\right)_{\mathrm{x}}(177.5)_{\mathrm{x}}$ : calculated [\%]: C 47.3, H 9.0, N 23.6, Cl 20.0; found [\%]: C 46.7, H 8.6, N 24.1, Cl 20.6.

Sodium toluene sulfonate $(11.4 \mathrm{~g}$, or $0.058 \mathrm{~mol})$ was added to a solution of [PHMG][Cl] $(10 \mathrm{~g}, 0.056 \mathrm{~mol})$ in $100 \mathrm{ml}$ of ethanol, and the mixture was stirred for 
Table 1. Chemical structure and basic physico-chemical characteristics of components under investigation.

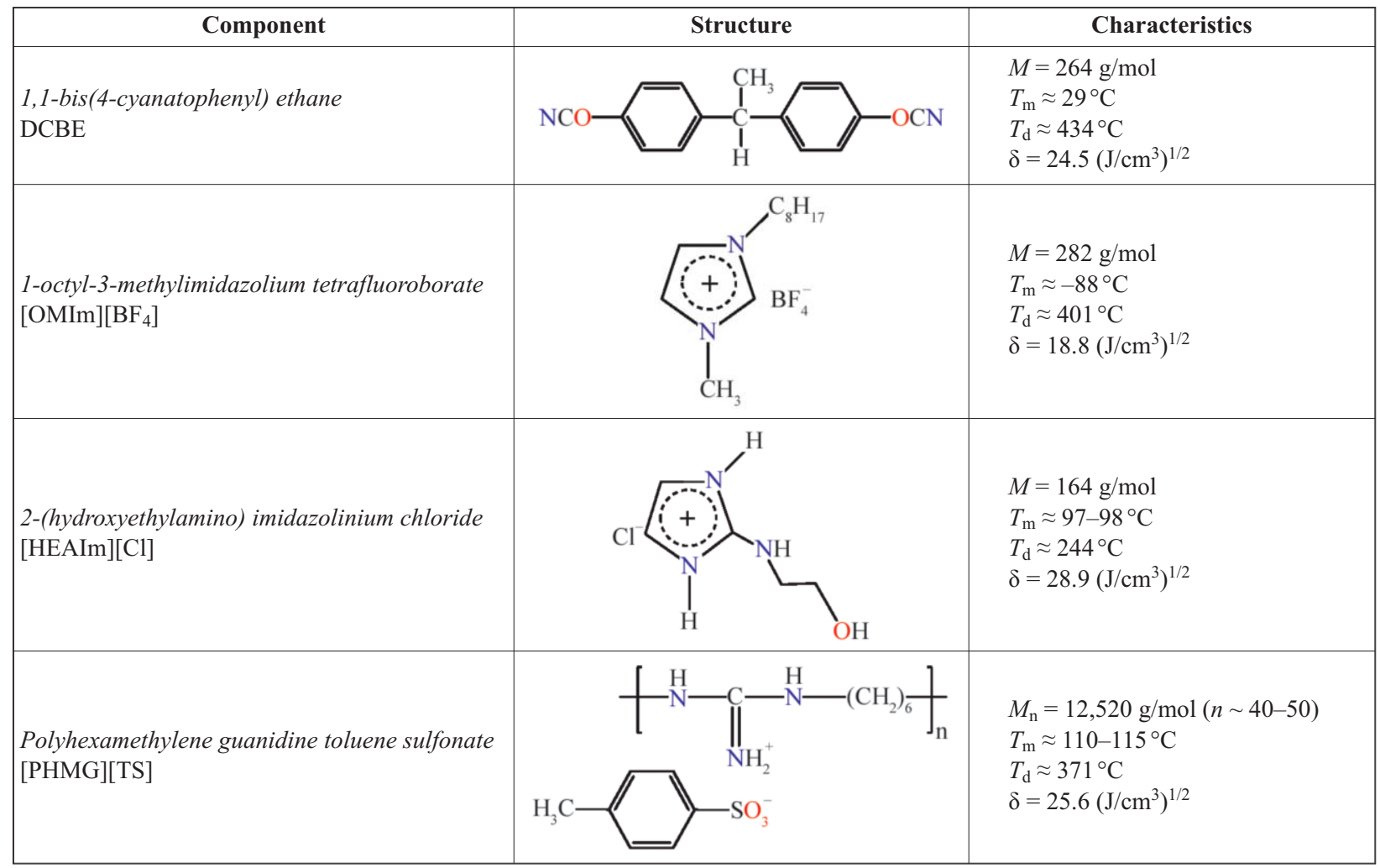

$20 \mathrm{~h}$ at room temperature. The resulting sodium chloride precipitate was filtered off, and the filtrate was poured into water $(300 \mathrm{ml})$. The white slurry was separated by decantation, followed by washing with water. It was dried at $120-130{ }^{\circ} \mathrm{C}$ for $24 \mathrm{~h}$ and ground to obtain [PHMG][TS] as a powder.

${ }^{1} \mathrm{H}$ NMR (300 MHz, DMSO- $\left.d_{6}\right): \delta$ [ppm]: $1.24(\mathrm{~m}$, $\left.4 \mathrm{H},\left(\mathrm{CH}_{2}\right)_{2}\right), 1.42\left(\mathrm{~m}, 4 \mathrm{H}, \mathrm{NCH}_{2} \mathrm{CH}_{2}\right), 2.29(\mathrm{~s}, 3 \mathrm{H}$, $\left.\mathrm{TsO}-\mathrm{CH}_{3}\right), 3.14$ (m, 4H, (NCH2), 7.14 (d, 2H, H-3, H-5), 7.3-7.35 (br s, 4H, C-NH, C= $\mathrm{NH}_{2}^{+}$), 7.53 (d, 2H, H-2, H-6).

Elemental analysis: $\left(\mathrm{C}_{14} \mathrm{H}_{23} \mathrm{~N}_{3} \mathrm{O}_{3} \mathrm{~S}\right)_{\mathrm{x}}(313)_{\mathrm{x}}$ : calculated: C 53.6, H 7.3, N 13.4, S 10.2; found: C 53.1, $\mathrm{H} 7.0, \mathrm{~N} 13.8, \mathrm{~S} 10.5$.

The chemical structure and some physico-chemical characteristics of individual components used in this study are summarized in Table 1 . The solubility parameters $(\delta)$ of DCBE and ILs were calculated according to Fedor's Group Contribution Method [25].

\subsection{Preparation of CER-based networks}

Mixtures of DCBE with $1.0 \mathrm{wt} \%$ IL were first stirred until homogeneous state as follows. DCBE monomer was mixed with $[\mathrm{OMIm}]\left[\mathrm{BF}_{4}\right],[\mathrm{HEAIm}][\mathrm{Cl}]$ or [PHMG][TS] at $T \sim 150^{\circ} \mathrm{C}$ for $\sim 3 \mathrm{~min}$, then the homogeneous DCBE/IL mixtures were polymerized by a step-by-step curing procedure with the following successive heating conditions: $150^{\circ} \mathrm{C} / 8 \mathrm{~h}, 180^{\circ} \mathrm{C} / 3 \mathrm{~h}$, $210^{\circ} \mathrm{C} / 3 \mathrm{~h}, 230^{\circ} \mathrm{C} / 1 \mathrm{~h}$.

The effect of IL chemical structure on the resulting $\mathrm{CER} /[\mathrm{OMIm}]\left[\mathrm{BF}_{4}\right], \mathrm{CER} /[\mathrm{HEAIm}][\mathrm{Cl}]$ or $\mathrm{CER} /$ [PHMG][TS] networks was studied by FTIR to detect possible chemical reactions between OCN groups of DCBE and functional groups of ILs. A model composition for DCBE/IL equal to $50 / 50 \mathrm{wt} \%$ was used at $150^{\circ} \mathrm{C}$ for $3 \mathrm{~min}$ to obtain homogeneous mixtures, followed by a step-by-step curing procedure with the following heating conditions: $150^{\circ} \mathrm{C} / 8 \mathrm{~h}$, $180^{\circ} \mathrm{C} / 3 \mathrm{~h}, 210^{\circ} \mathrm{C} / 3 \mathrm{~h}, 230^{\circ} \mathrm{C} / 1 \mathrm{~h}$.

\subsection{Physico-chemical techniques}

${ }^{1} \mathrm{H}$ NMR and ${ }^{19} \mathrm{~F}$ NMR techniques were used to characterize the ionic liquids synthesized. The spectra were recorded with a Varian (300 MHz) NMR spectrometer at $23^{\circ} \mathrm{C}$ using DMSO- $d_{6}$ as the deuterated solvent.

Elemental analysis of the ionic liquids synthesized was performed using classical approaches described elsewhere [24].

For kinetic measurements by FTIR, neat DCBE or DCBE/IL mixtures of 99/1 wt $\%$ compositions were poured directly onto $\mathrm{NaCl}$ windows, followed by their isothermal heating in a temperature-controlled oven at $150^{\circ} \mathrm{C}$ for $8 \mathrm{~h}$ with periodic sampling out 
(every $30 \mathrm{~min}$ ). FTIR spectra were recorded at room temperature between 4000 and $600 \mathrm{~cm}^{-1}$ using a Bruker Tensor 37 spectrometer. For each spectrum, 32 consecutive scans with a resolution of $4 \mathrm{~cm}^{-1}$ were averaged.

The IR band at $1500 \mathrm{~cm}^{-1}$ of benzene ring vibrations was used as an internal standard. DCBE conversion was determined by monitoring the disappearance of $-\mathrm{O}-\mathrm{C} \equiv \mathrm{N}$ stretching band at $2266 \mathrm{~cm}^{-1}$. The conversion $\left(\alpha_{c}\right)$ of cyanate groups was calculated using Equation (1):

$\alpha_{\mathrm{c}}=\left(1-\frac{I_{(\mathrm{t}) 2266}-I_{(0) 2266}}{I_{(\mathrm{t}) 1500}-I_{(0) 1500}}\right) \cdot 100$

where $I_{(\mathrm{t}) 2266}$ is the intensity of $\mathrm{C} \equiv \mathrm{N}$ vibration band in $-\mathrm{O}-\mathrm{C} \equiv \mathrm{N}$ at $2266 \mathrm{~cm}^{-1}$ at time $t ; I_{(\mathrm{t}) 1500}$ is the intensity of carbon-carbon stretching vibrations in aromatic ring band at $1500 \mathrm{~cm}^{-1}$ at time $t ; I_{(0)}$ is the intensity of corresponding vibration bands in the initial DCBE-containing mixture.

Thermogravimetric analysis (TGA) measurements were performed using a Setaram SETSYS evolution 1750 thermobalance. Samples were heated in a platinum crucible from 20 to $700^{\circ} \mathrm{C}$ at a heating rate of $10^{\circ} \mathrm{C} \cdot \mathrm{min}^{-1}$ under argon atmosphere. The sample mass was about $10 \mathrm{mg}$.

Dynamic mechanical thermal analysis (DMTA) was carried out using a DMA-Q800 equipment (TA Instruments) in a temperature range from 20 to $350^{\circ} \mathrm{C}$ at a heating rate of $4{ }^{\circ} \mathrm{C} / \mathrm{min}$ and frequency values of $1,3,5,10,15$ and $20 \mathrm{~Hz}$ using single cantilever bending mode. Rectangular samples of size $40 \times 5 \times 1 \mathrm{~mm}$ were tested.

The apparent activation energy $\left(\Delta E_{\mathrm{a}}\right)$ for $\alpha$ relaxation was determined by applying the Vogel-Fulcher-Tammann (VFT) equation as follows (Equation 2) [26-29]:

$f=f_{0} \exp \left(-\frac{\Delta E_{\mathrm{a}}}{R\left(T-T_{\mathrm{VFT}}\right)}\right)$

where $f$ represents the test frequency, $f_{0}$ stands for the extrapolated frequency at $T=0 \mathrm{~K}, R$ is the gas constant $\left(R=8.314 \cdot 10^{-3} \mathrm{~kJ} \cdot \mathrm{mol}^{-1} \cdot \mathrm{K}^{-1}\right), T$ stands for absolute temperature, $T_{\mathrm{VFT}}$ is about $50^{\circ} \mathrm{C}$ lower than the $\alpha$ transition temperature $T_{\alpha}$.

The shift of $\alpha$ relaxation temperatures $\left(T_{\alpha 1}\right.$ and $\left.T_{\alpha 2}\right)$ due to changes in the test frequencies $\left(f_{1}\right.$ and $\left.f_{2}\right)$ allows for the determination of $\Delta E_{\mathrm{a}}$ values by using Equations (3), (4) and (5) [30]:

$$
\begin{aligned}
& \frac{f_{1}}{f_{2}}=\frac{\exp \left(\frac{-\Delta E_{\mathrm{a}}}{R\left(T_{\alpha 1}-T_{\mathrm{VFT}}\right)}\right)}{\exp \left(\frac{-\Delta E_{\mathrm{a}}}{R\left(T_{\alpha 2}-T_{\mathrm{VFT}}\right)}\right)} \\
& \log \left(\frac{f_{1}}{f_{2}}\right)=\log \alpha_{\mathrm{T}}= \\
& =\frac{\Delta E_{\mathrm{a}}}{R}\left(\frac{1}{T_{\alpha 2}-T_{\mathrm{VFT}}}-\frac{1}{T_{\alpha 1}-T_{\mathrm{VFT}}}\right) \log \mathrm{e} \\
& \Delta E_{\mathrm{a}}=-R\left(\frac{d(\ln f)}{d\left(\frac{1}{T_{\alpha}-T_{V F T}}\right)}\right)
\end{aligned}
$$

\section{Results and discussion \\ 3.1. Investigation of the curing process by FTIR}

Kinetics of neat CER formation and DCBE polymerization in the presence of [OMIm] $\left[\mathrm{BF}_{4}\right],[\mathrm{HEAIm}][\mathrm{Cl}]$ or $[\mathrm{PHMG}][\mathrm{TS}]$ was investigated by FTIR. The normalized FTIR spectra of corresponding networks during their isothermal curing at $150^{\circ} \mathrm{C}$ are shown in Figure 2. The absorption doublet at $2266-2237 \mathrm{~cm}^{-1}$ corresponding to $-\mathrm{O}-\mathrm{C} \equiv \mathrm{N}$ group stretching vibrations diminished with the curing time for pure CER as well as for all the CER/IL networks, while the bands at 1565 and $1369 \mathrm{~cm}^{-1}$, respectively corresponding to valence vibrations of $\mathrm{C}=\mathrm{N}$ bonds $\left(v_{\mathrm{C}=\mathrm{N}}\right)$ in $\mathrm{C}=\mathrm{N}-\mathrm{C}$ groups and $\mathrm{N}-\mathrm{C}$ bonds $\left(v_{\mathrm{N}-\mathrm{C}}\right)$ in $\mathrm{N}-\mathrm{C}-\mathrm{O}$ groups of cyanurate cycles, appeared $[1,2]$.

The time dependence of cyanate group conversion $\left(\alpha_{c}\right)$ and reaction rate $(W=\mathrm{d} \alpha / \mathrm{d} t)$ for neat CER and $\mathrm{CER} / \mathrm{IL}$ networks is shown in Figure 3. For pure CER, the induction period of DCBE polycyclotrimerization was equal to about $60 \mathrm{~min}$, whereas for $\mathrm{CER} /[\mathrm{OMIm}]\left[\mathrm{BF}_{4}\right], \mathrm{CER} /[\mathrm{HEAIm}][\mathrm{Cl}]$ and $\mathrm{CER} /$ [PHMG][TS], the induction period was by $1.5-3.0$ times shorter, depending on IL structure (Table 2). In addition, the maximal rate of reaction, $W_{\max }$, increased by $10-20 \%$ and the time to maximal rate of reaction, $t_{\max }$, decreased by $7-42 \%$ (Table 2 ). Therefore, the introduction of ILs into the DCBE reaction medium significantly accelerated the conversion of $-\mathrm{O}-\mathrm{C} \equiv \mathrm{N}$ groups from the early stages of CER network formation. It should be noticed that conversion of $-\mathrm{O}-\mathrm{C} \equiv \mathrm{N}$ groups reached the value of $\alpha_{\mathrm{c}} \sim 0.98$ for all the CER networks synthesized after the complete curing schedule.

Further, for all CER-based systems, the reaction rate increased dramatically in the kinetic-controlled stage (linear part of conversion vs. time curve in Figure 3a) 

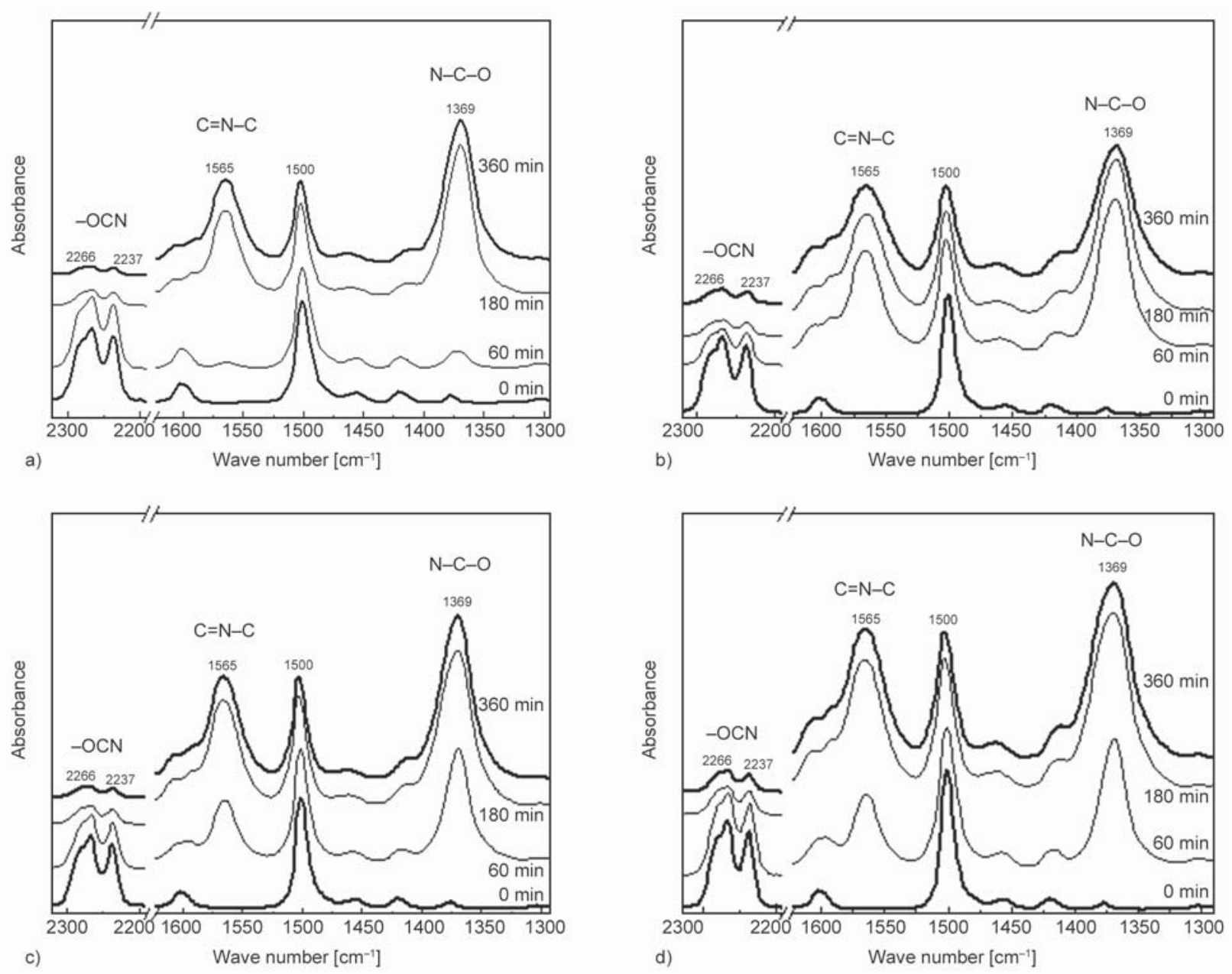

Figure 2. Typical FTIR spectra in 2320-1290 $\mathrm{cm}^{-1}$ region during curing procedure for: (a) neat CER, (b) CER/[OMIm] $\left.\mathrm{BF}_{4}\right]$, (c) $\mathrm{CER} /[\mathrm{HEAIm}][\mathrm{Cl}]$, and (d) CER/[PHMG][TS]. The spectra were shifted vertically for the sake of clarity.

until it reached a maximum $W_{\max }$ (Figure $3 \mathrm{~b}$ ). After reaching the gel point, the reaction rate decreased drastically as the polymerization process became

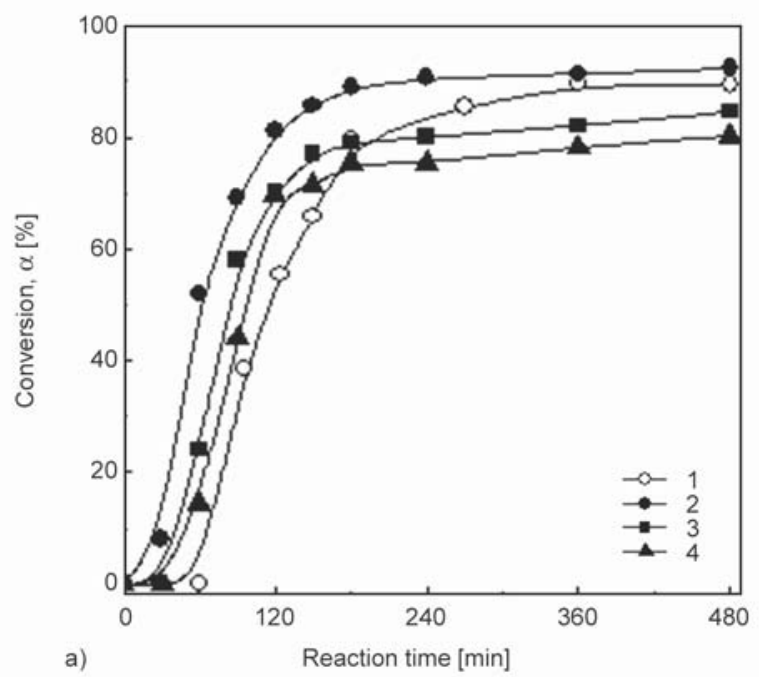

diffusion-limited. For all the CER/IL networks, the reaction was faster compared to neat CER (completion after about $360 \mathrm{~min}$ ).

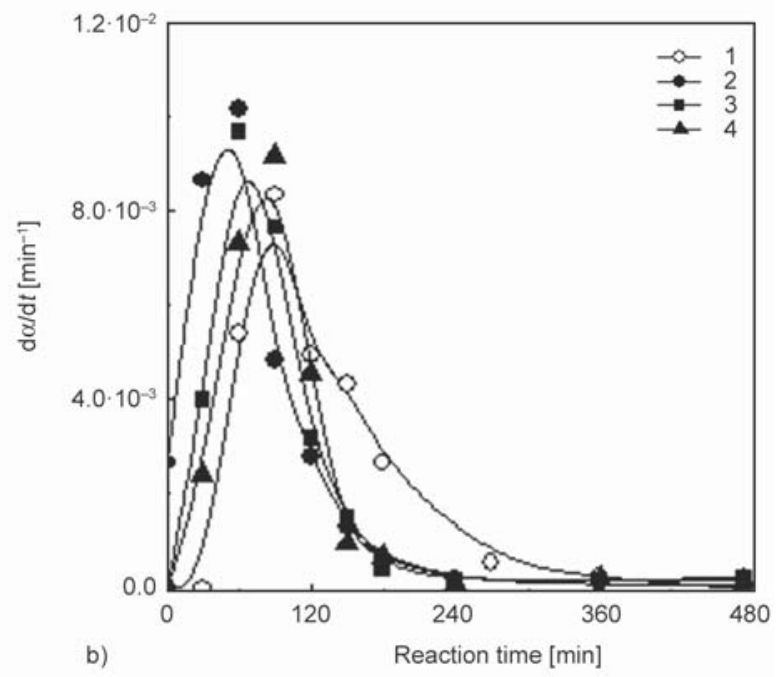

Figure 3. Kinetic curves at $T=150^{\circ} \mathrm{C}$ : time dependence of (a) conversion $\left(\alpha_{\mathrm{c}}\right)$ of $-\mathrm{OCN}$ groups from DCBE and (b) reaction rate $\left(\mathrm{d} \alpha / \mathrm{d}_{\mathrm{t}}\right)$. Neat CER (1), CER/[OMIm] [BF 4 (2), CER/[HEAIm] [Cl] (3), and DCBE/[PHMG][TS] (4). 
Table 2. Kinetic parameters of DCBE polymerization in the absence and the presence of $1.0 \mathrm{wt} \%$ IL.

\begin{tabular}{|c|c|c|c|c|}
\hline Network & $\begin{array}{c}t_{\mathrm{i}}^{\mathrm{a}} \\
{[\mathrm{min}]}\end{array}$ & $\begin{array}{c}W_{\max } \cdot 10^{3 \mathrm{~b}} \\
{\left[\min ^{-1}\right]}\end{array}$ & $\begin{array}{l}t_{\max } \mathrm{c} \\
{[\mathrm{min}]}\end{array}$ & $\begin{array}{c}\boldsymbol{\alpha}_{\mathrm{c}}^{\mathrm{d}} \\
{[\%]}\end{array}$ \\
\hline Neat CER & 60 & 8.4 & 89 & 89 \\
\hline $\mathrm{CER} /[\mathrm{OMIm}]\left[\mathrm{BF}_{4}\right]$ & 20 & 10.2 & 52 & 91 \\
\hline CER / [HEAIm][Cl] & 34 & 9.7 & 68 & 82 \\
\hline CER / [PHMG][TS] & 40 & 9.2 & 83 & 78 \\
\hline
\end{tabular}

ainduction period

${ }^{b}$ maximal rate of reaction $(W=\mathrm{d} \alpha / \mathrm{d} t)$

ctime to maximal rate of reaction

${ }^{\mathrm{d}}$ maximal conversion of $-\mathrm{OCN}$ groups

\section{2. $\mathrm{CER} / \mathrm{IL}$ curing mechanisms}

The curing mechanisms of CER/IL composites were studied on model reactions starting from DCBE/IL mixtures with a $50 / 50 \mathrm{wt} \%$ composition. The spectrum of $\mathrm{CER} /[\mathrm{OMIm}]\left[\mathrm{BF}_{4}\right]$ showed only characteristic absorbance bands of both individual components (see Figure 4, curve (3)) that evidenced the chemical inertness of $[\mathrm{OMIm}]\left[\mathrm{BF}_{4}\right]$ towards DCBE. In a previous work [31], we have already proposed the mechanism of DCBE polymerization in the presence of $[\mathrm{OMIm}]\left[\mathrm{BF}_{4}\right]$ via the formation of a $[\mathrm{CN}]^{\delta+}-[\mathrm{OMIm}]^{\delta-}$ complex as a key intermediate (Figure 5).

One could suppose the same mechanism for DCBE polymerization in the presence of [HEAIm] [Cl]. However, in the latter case, the competition between the catalytic complex formation and the covalent bonding through the reaction of cyanate groups of DCBE with $-\mathrm{OH}$ and $>\mathrm{NH}$ groups of [HEAIm] [Cl] should be considered. Thus, a three-step mechanism

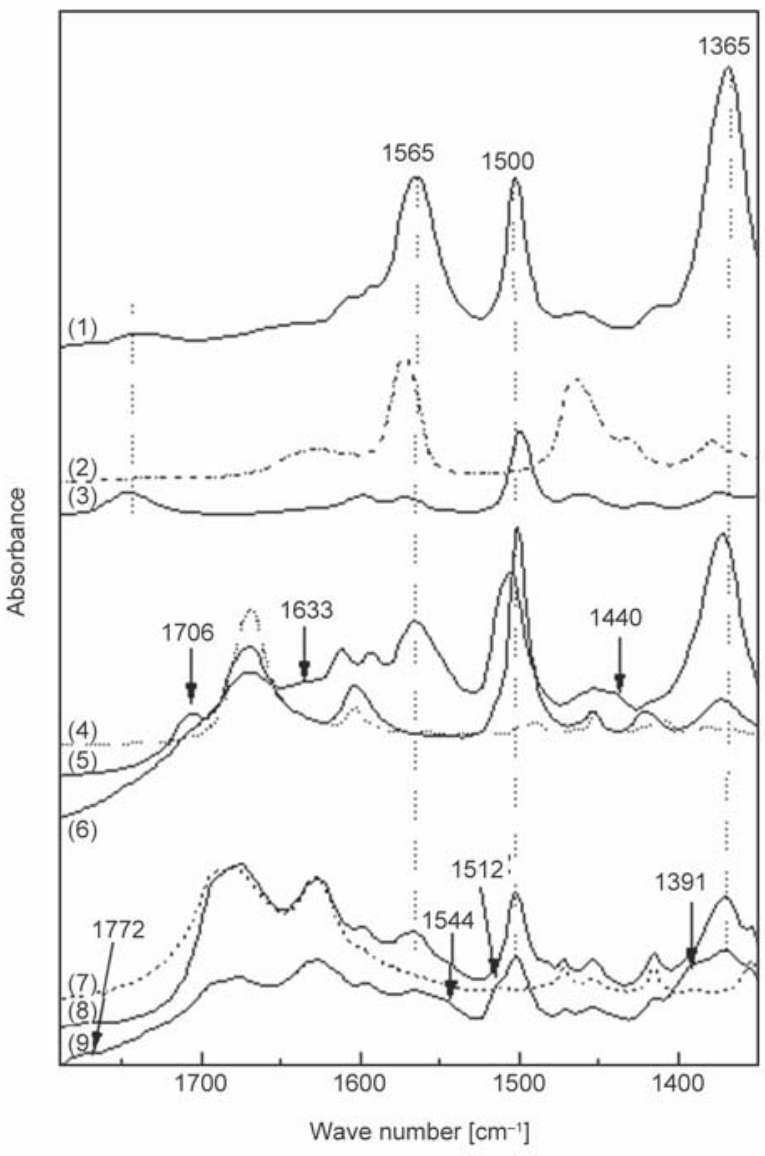

Figure 4. FTIR spectra in $1780-1350 \mathrm{~cm}^{-1}$ region for:

(1) neat CER, (2) [OMIm] $\left[\mathrm{BF}_{4}\right]$,

(3) $\mathrm{CER} /[\mathrm{OMIm}]\left[\mathrm{BF}_{4}\right] 50 / 50 \mathrm{wt} \%$,

(4) $[\mathrm{HEAIm}][\mathrm{Cl}],(5) \mathrm{DCBE} /[\mathrm{HEAIm}][\mathrm{Cl}]$

$50 / 50 \mathrm{wt} \%$ before curing, (6) CER/[HEAIm] [Cl] $50 / 50 \mathrm{wt} \%$ after curing, (7) [PHMG][TS],

(8) DCBE/[PHMG][TS] 50/50 wt $\%$ before curing, (9) $\mathrm{CER} /[\mathrm{PHMG}][\mathrm{TS}] 50 / 50 \mathrm{wt} \%$ after curing. The spectra were shifted vertically for the sake of clarity.

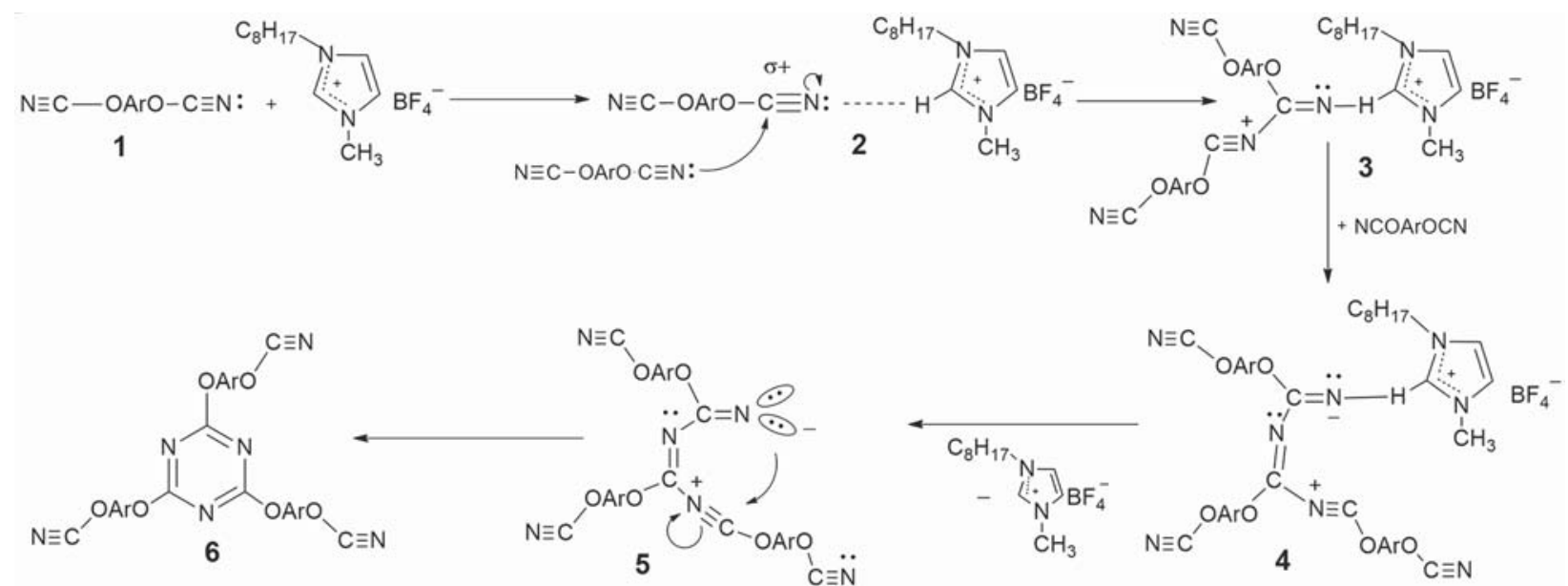

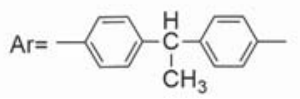

Figure 5. Proposed mechanism for $[\mathrm{OMIm}]\left[\mathrm{BF}_{4}\right]$-catalyzed DCBE polycyclotrimerization. 
was proposed for the formation of cyanurate cycles from DCBE polymerization being catalyzed by [HEAIm] [Cl] (Figure 6). Our hypothesis was based on the well-known mechanisms of polycyclotrimerization of CERs in the presence of hydroxy [1, 32$35]$ and amino [36, 37] compounds. First, during the mixing procedure, the $-\mathrm{OCN}$ groups of $\mathrm{DCBE}$ could react with hydroxyl groups of [HEAIm] [Cl] with formation of imidocarbonate $\mathrm{O}-\mathrm{C}(=\mathrm{NH})-\mathrm{O}$ fragment (Figure 6, compound 2), which further reacted with a second DCBE molecule with formation of a stabilized dimer (Figure 6, compound 3). A third DCBE molecule reacted with the dimer 3 , thus giving rise to the intermediate 4 , which was further transformed into the triazine ring. This transformation could be potentially followed by two mechanisms: either [HEAIm] $[\mathrm{Cl}]$ release leading to product 5 (cyanurate cycle) or [HEAIm] $[\mathrm{Cl}]$ incorporation directly into the cyanurate network (Figure 6, compound 6) with release of $\mathrm{ROH}$ (monocyanate of bisphenol E). According to Grigat and Pütter [36] as well as our previous works [33-35], the more acidic phenol compared to alcohol was released, and thus, a substituted triazine ring should be obtained with the release of a monophenol derived from DCBE. Moreover, we presumed that $[\mathrm{HEAIm}][\mathrm{Cl}]$ could also increase the polarization of the $\mathrm{C}=\mathrm{N}$ bond in the imidocarbonate (Figure 6, compound 2), thus making the carbon atom of this functional group more electrophilic. This was confirmed by FTIR through the appearance of a shoulder at $1440 \mathrm{~cm}^{-1}$ attributed to $\mathrm{N}-\mathrm{C}=\mathrm{O}$ asymmetric vibrations along with a band at $1706 \mathrm{~cm}^{-1}$, which could be related to $\mathrm{C}=\mathrm{O}$ stretching vibrations in the urea linkage of imidazolidinone (Figure 6, compound 4'; see Figure 4, curve (6)) [38]. The formation of compound $\mathbf{4}^{\prime}$ from $\mathbf{2}$ might be possible upon releasing of monophenol derivative through the formation of iminooxazolidine $\mathbf{3}^{\prime}$, which could also be accompanied by its partial isomerization into compound $4^{\prime}$. Furthermore, the reaction between the secondary $>\mathrm{NH}$ groups of [HEAIm] $[\mathrm{Cl}]$, which were less reactive than $-\mathrm{OH}$ groups, was possible as well.

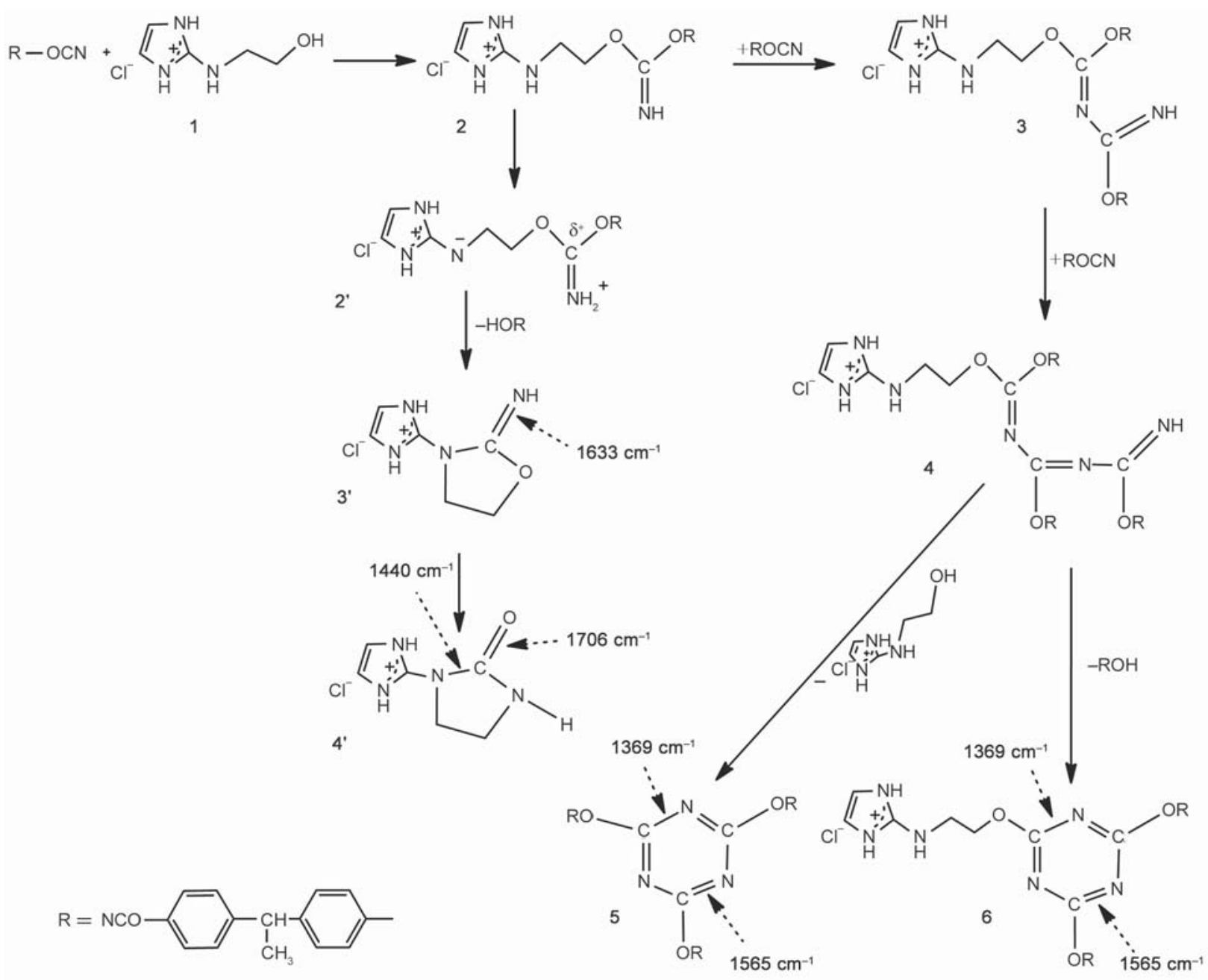

Figure 6. Proposed mechanism for [HEAIm] [Cl]-catalyzed DCBE polycyclotrimerization. 


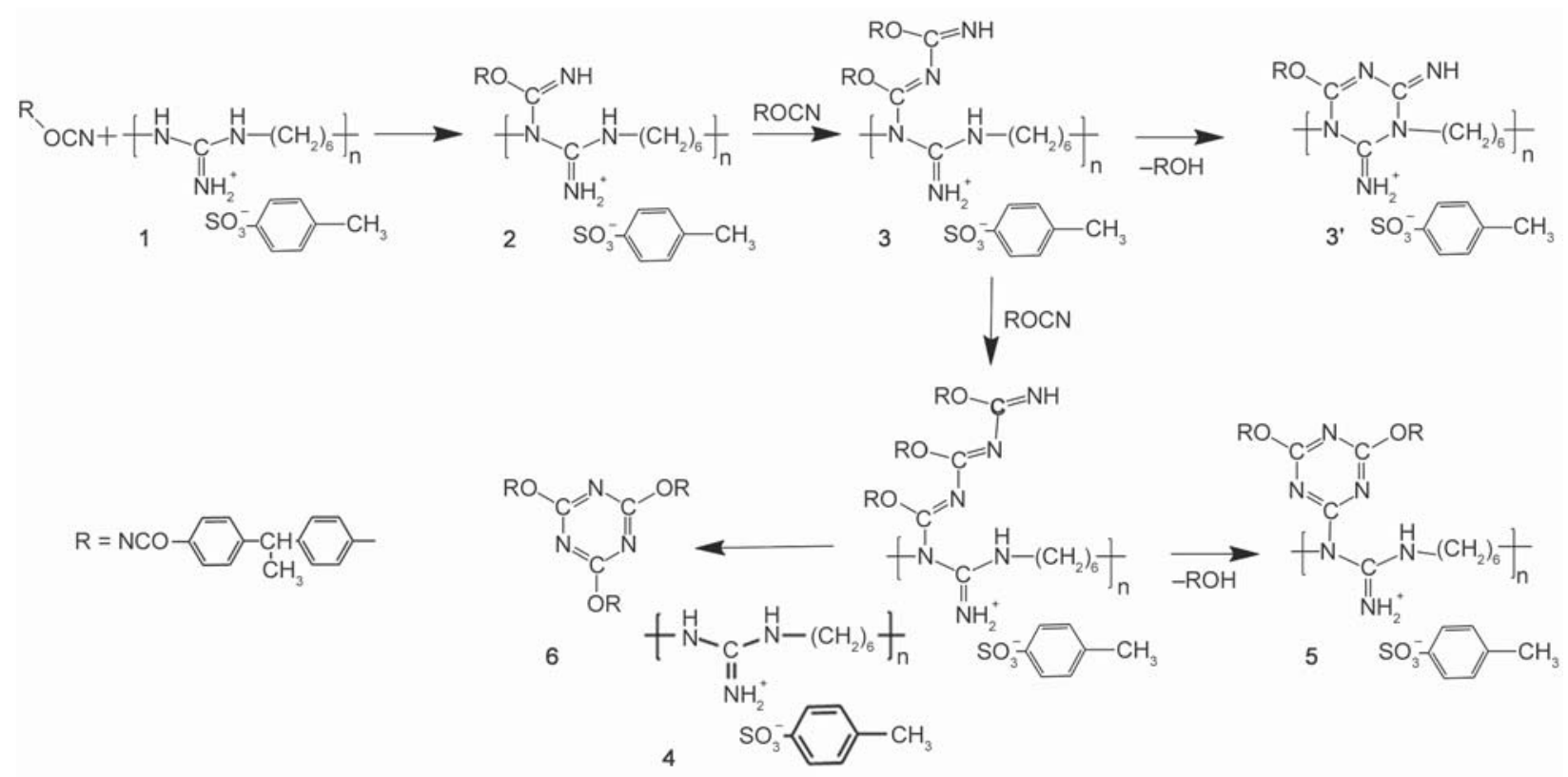

Figure 7. Proposed mechanism for [PHMG][TS]-catalyzed DCBE polycyclotrimerization.<smiles></smiles><smiles></smiles>

Figure 8. Chemical reaction between cyanate groups of DCBE and traces of water or phenol impurity accompanying the DCBE monomer.

The occurrence of structure $\mathbf{3}^{\prime}$ was confirmed by FTIR with the appearance of a shoulder at $1633 \mathrm{~cm}^{-1}$ assigned to the $\mathrm{N}-\mathrm{H}$ in the isourea linkage [39] (see Figure 4, curve (6)), which seemed to be formed together with the cyanurate-based compounds (Figure 6, compounds 5 and 6). Accordingly, hybrid chemical structures with additional network junctions could be produced for the CER/ [HEAIm] $[\mathrm{Cl}]$ system.

The proposed mechanism of DCBE polycyclotrimerization process in the presence of [PHMG][TS] was also based on the reactivity of secondary amino groups towards cyanate groups, as represented schematically in Figure 7. The new strong absorption FTIR bands around 1565 and $1369 \mathrm{~cm}^{-1}$ could be attributed to the $\mathrm{C}=\mathrm{N}-\mathrm{C}$ and $\mathrm{O}-\mathrm{C}-\mathrm{N}$ stretching vibrations in cyanurate groups. Two routes of grafting of [PHMG][TS] polymer chains onto the CER network structure were possible. Meanwhile, the existence of a new group conjugated to a triazine ring was proved by the FTIR bands at around $1544 \mathrm{~cm}^{-1}\left(v_{\mathrm{C}=\mathrm{N}}\right)[40]$ and $1512 \mathrm{~cm}^{-1}$ attributed to aromatic ring stretching vibrations
(Figure 7, compound 3'; see Figure 4, curve (9)). The absorption band at $1391 \mathrm{~cm}^{-1}$ could be assigned to the stretching vibrations $v_{\mathrm{N}-\mathrm{C}}[41]$ associated with groups bridging the triazine rings (Figure 7, compound 4). All these observations confirmed the [PHMG][TS] incorporation into the polycyanurate network structure.

Additionally, a band at $1772 \mathrm{~cm}^{-1}$ attributed to $\mathrm{C}=\mathrm{O}$ stretching vibrations appeared in the FTIR spectra of both initial DCBE/[PHMG][TS] mixture and CER/ [PHMG][TS] after complete curing (see Figure 4, curves (8) and (9)). We could suppose that the reaction of cyanate groups from DCBE and CER with traces of water [42] or phenolic impurity could occur to generate an imidocarbonate intermediate (Figure 8).

\subsection{Thermal stability of CER-based networks by TGA}

The thermal stability of CER/IL networks as well as individual components (i.e., neat CER and ILs) was investigated by TGA (Figure 9, Table 3). It is noteworthy that all CER/ILs networks exhibited high 

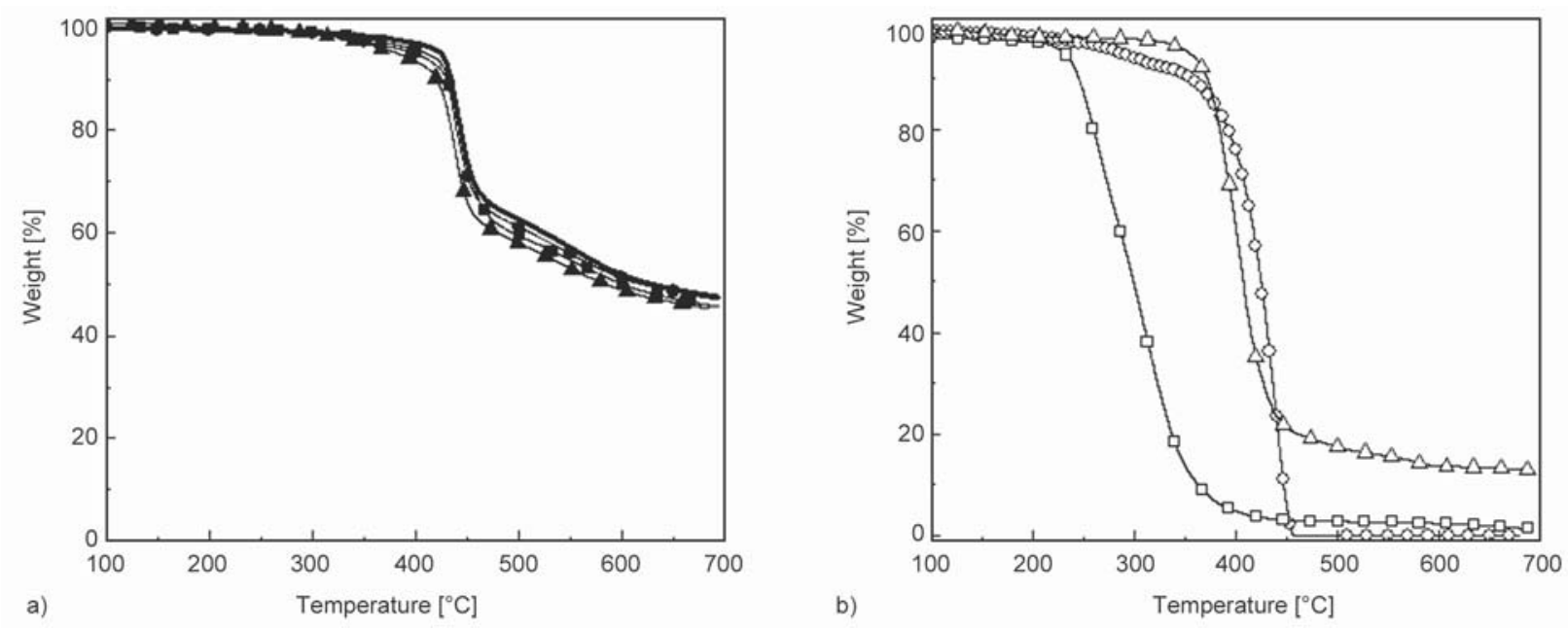

Figure 9. TGA curves for (a) CER-based networks and (b) pure ILs: neat CER (-), CER/[OMIm] $\left[\mathrm{BF}_{4}\right](-\bullet-)$,

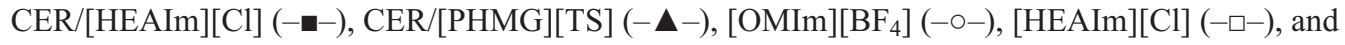
$[\mathrm{PHMG}][\mathrm{TS}](-\triangle-)$.

thermal stability, similarly to pure CER, as no visible mass loss was observed at temperatures below $420^{\circ} \mathrm{C}$. For all the CER-based networks, the main degradation stage occurred in a temperature range from $T_{\mathrm{d} \text { onset }} \approx 420-427^{\circ} \mathrm{C}$ to $T_{\mathrm{d} \text { end }} \approx 450-460^{\circ} \mathrm{C}$, depending on IL structure. One could also observe some weak degradation stage in a temperature range of $T \approx$ $500-640^{\circ} \mathrm{C}$ for all the samples under investigation, which could be attributed to CER mass loss due to the elimination of alkenes and hydrogen, leaving a carbonaceous char containing residual oxygen and nitrogen [43, 44].

The thermal stability of CER/[OMIm] $\left[\mathrm{BF}_{4}\right]$ and $\mathrm{CER} /[\mathrm{HEAIm}][\mathrm{Cl}]$ was quite similar to that of neat CER (see Figure 9, Table 3). This meant that using $1.0 \mathrm{wt} \%$ of corresponding ILs did not change significantly the chemical structure and cross-linking density of the CER network. We considered that one such behavior resulted from the fact that $[\mathrm{OMIm}]\left[\mathrm{BF}_{4}\right]$ had no chemical bonds with the CER network (cf.
Figure 5). [HEAIm] $] \mathrm{Cl}]$ had a covalent grafting with the cyanurate network but the molecular mass of the IL molecules was too small $(M=164 \mathrm{~g} / \mathrm{mol}$, see Table 1), and above all, an amount of $1.0 \mathrm{wt} \%$ was too low to significantly change the chemical structure and notably the cross-linking structure of the CER matrix. Interestingly, despite a thermal stability of pure [HEAIm] [Cl] substantially lower than that of other ILs and neat CER (Figure 9b, Table 3), the careful analysis of the TGA curve of the CER/[HEAIm][Cl] network did not show the corresponding mass loss (i.e. $1.0 \mathrm{wt} \%$ ) of the IL in the temperature range in which the main degradation of pure IL occurred. Therefore, the highly crosslinked CER network might prevent the IL from regular thermal degradation, probably due to its chemical incorporation into the CER matrix (see Figure 6).

On the contrary, the CER/[PHMG][TS] network was characterized by a lower thermal stability compared to the other analogues (cf. Table 3). Obviously enough,

Table 3. Thermal stability of CER-based networks and pure ILs as investigated by TGA.

\begin{tabular}{|c|c|c|c|c|}
\hline Sample & $\begin{array}{c}T_{\text {d onset }}{ }^{\mathrm{a}} \\
{\left[{ }^{\circ} \mathrm{C}\right]}\end{array}$ & $\begin{array}{c}T_{\mathrm{d} \max }{ }^{\mathrm{b}} \\
{\left[{ }^{\circ} \mathrm{C}\right]}\end{array}$ & $\begin{array}{l}\Delta m^{\mathrm{c}} \\
{[\%]}\end{array}$ & $\begin{array}{c}\text { Char residue at } 680^{\circ} \mathrm{C} \\
{[\%]}\end{array}$ \\
\hline Neat CER & 427 & 441 & 33.7 & 47.5 \\
\hline $\mathrm{CER} /[\mathrm{OMIm}]\left[\mathrm{BF}_{4}\right]$ & 425 & 443 & 33.1 & 46.7 \\
\hline CER/[HEAIm][Cl] & 424 & 443 & 35.1 & 45.7 \\
\hline CER/[PHMG][TS] & 420 & 438 & 34.3 & 45.4 \\
\hline$[\mathrm{OMIm}]\left[\mathrm{BF}_{4}\right]$ & 396 & 439 & 91.3 & 0.0 \\
\hline$[\mathrm{HEAIm}][\mathrm{Cl}]$ & 240 & 295 & 94.2 & 1.3 \\
\hline [PHMG][TS] & 372 & 403 & 78.1 & 13.0 \\
\hline
\end{tabular}

${ }^{\mathrm{a}} T_{\mathrm{d}}$ onset: onset temperature for intensive degradation stage considered

${ }^{\mathrm{b}} T_{\mathrm{d} \text { max }}$ : temperature of maximum degradation rate for intensive stage considered

${ }^{\mathrm{c}} \Delta m$ : mass loss for intensive degradation stage considered 
one such behavior might arise from the formation of a CER network with lower cross-linking density and structural regularity, due to the chemical incorporation of relatively long linear polymer fragments of [PHMG][TS] $\left(M_{\mathrm{n}}=12520 \mathrm{~g} / \mathrm{mol}\right.$, see Table 1$)$ into the CER matrix.

\subsection{Viscoelastic properties of CER-based networks by DMTA}

Figure 10 shows the temperature dependence of storage modulus $\left(E^{\prime}\right)$ and loss factor $(\tan \delta)$ for neat CER and CER/IL networks. All the samples were characterized by high $\alpha$ relaxation temperature values $\left(T_{\alpha}>\right.$ $240^{\circ} \mathrm{C}$, Table 4), as typically found for thermostable cross-linked polymers, due to high temperature resistance of cross-links and high cross-linking density of polymer networks [1-6, 32-35].

Unpredictably, a significant effect of the low IL content (i.e., $1.0 \mathrm{wt} \%$ ) on the viscoelastic properties of all CER/IL networks was found compared to those of pure CER (Figure 10, Table 4). However, the lowest changes were observed for the $\mathrm{CER} /[\mathrm{OMIm}]\left[\mathrm{BF}_{4}\right]$ network. This was probably due to the fact that $[\mathrm{OMIm}]\left[\mathrm{BF}_{4}\right]$ was not chemically embedded into the CER network structure [31]. Nevertheless, a slight decrease in $T_{\alpha}$ and $E^{\prime}$ values as well as an increase in $\tan \delta_{\max }$ and $\Delta T$ values were evidenced, thus demonstrating a higher mobility of the kinetic segments between the cross-links of the CER matrix.

On the contrary, the chemical incorporation of [HEAIm] $[\mathrm{Cl}]$ and especially [PHMG][TS] into the CER matrix resulted in a substantial decrease in the values of $T_{\alpha}$ as well as a significant rise in values of $\tan \delta_{\max }$ and $\Delta T$ compared to those for neat CER. Again, these facts evidenced the increase in mobility of the kinetic segments within the CER matrix, due to the reduced cross-linking density of the polycyanurate network in the CER/IL samples. Such changes turned out to be more drastic for the CER/ [PHMG][TS] network, due to the chemical incorporation of polymeric chains from the IL into the CER network compared to the grafting of small molecules of [HEAIm] $[\mathrm{Cl}]$ into the corresponding CER matrix. For the CER/[PHMG][TS] network, a dramatic

Table 4. Viscoelastic properties of CER-based networks as investigated by DMTA.

\begin{tabular}{|c|c|c|c|c|c|c|c|c|}
\hline \multirow[t]{2}{*}{ Network } & \multirow{2}{*}{$\begin{array}{c}T_{\mathbf{a}}{ }^{a} \\
{\left[{ }^{\circ} \mathbf{C}\right]}\end{array}$} & \multirow[t]{2}{*}{$\tan \delta_{\max }$} & \multirow{2}{*}{$\begin{array}{l}\Delta \boldsymbol{T}^{\mathrm{b}} \\
{\left[{ }^{\circ} \mathbf{C}\right]}\end{array}$} & \multirow{2}{*}{$\begin{array}{c}\Delta E_{\mathrm{a}}^{\mathrm{c}} \\
{[\mathrm{kJ} / \mathrm{mol}]}\end{array}$} & \multicolumn{3}{|c|}{$\begin{array}{c}E^{\prime} \\
{[\mathrm{GPa}]}\end{array}$} & \multirow{2}{*}{$\begin{array}{c}T_{\text {pc(onset) }}{ }^{\mathrm{d}} \\
{\left[{ }^{\circ} \mathrm{C}\right]}\end{array}$} \\
\hline & & & & & $20^{\circ} \mathrm{C}$ & $200^{\circ} \mathrm{C}$ & $250^{\circ} \mathrm{C}$ & \\
\hline Neat CER & 263 & 0.38 & 33 & 292 & 2.2 & 1.6 & 0.60 & 288 \\
\hline $\mathrm{CER} /[\mathrm{OMIm}]\left[\mathrm{BF}_{4}\right]$ & 262 & 0.52 & 40 & 286 & 2.1 & 1.4 & 0.56 & 277 \\
\hline $\mathrm{CER} /[\mathrm{HEAIm}][\mathrm{Cl}]$ & 248 & 0.67 & 40 & 255 & 2.3 & 1.5 & 0.10 & 268 \\
\hline CER/[PHMG][TS] & 242 & 0.68 & 42 & 196 & 1.6 & 0.8 & 0.02 & 260 \\
\hline
\end{tabular}

${ }^{\mathrm{a}} T_{\alpha}: \alpha$ relaxation temperature

${ }^{\mathrm{b}} \Delta T$ : temperature width at $1 / 2 \tan \delta_{\max }$ height

${ }^{\mathrm{c}} \Delta E_{\mathrm{a}}$ : apparent activation energy of $\alpha$ relaxation

${ }^{\mathrm{d}} T_{\text {pc(onset): }}$ onset of temperature of CER post-curing as determined from $E^{\prime}=f(T)$
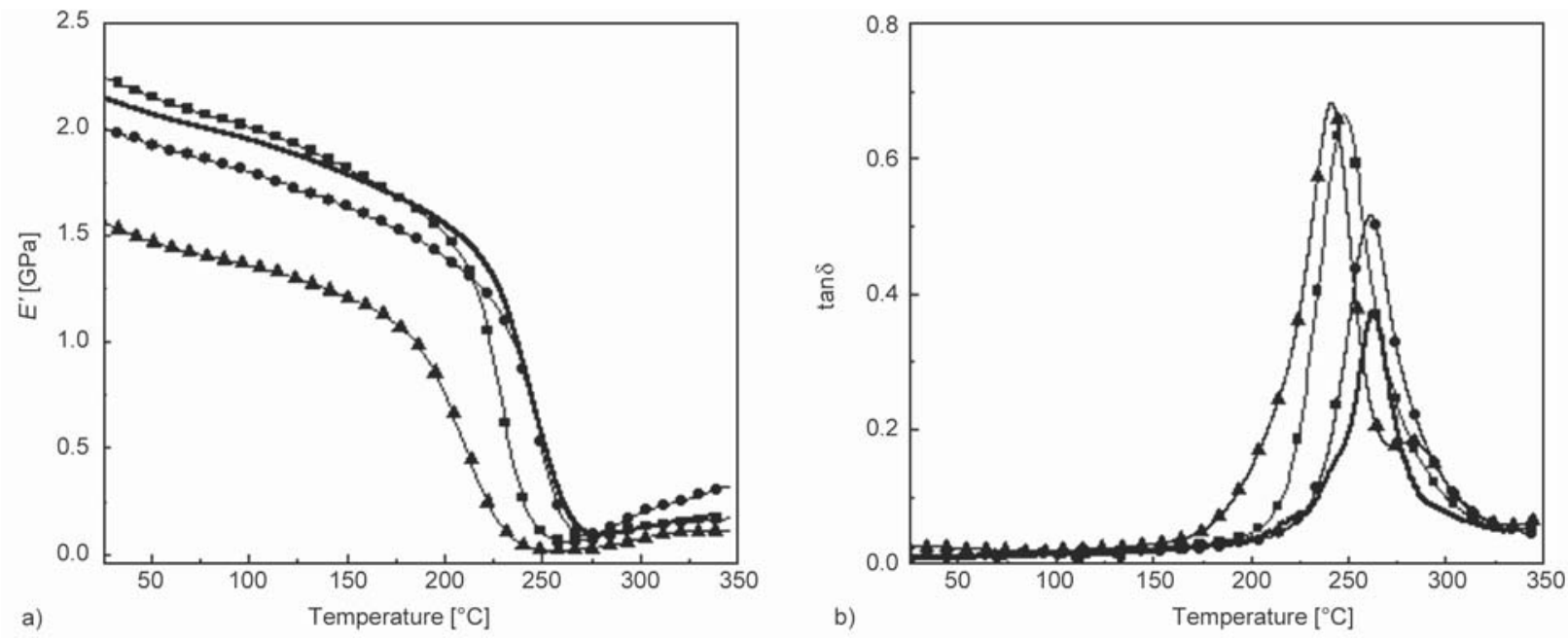

Figure 10. Plot of (a) $E^{\prime}$ and (b) $\tan \delta$ as a function of temperature at $1 \mathrm{~Hz}$ for: CER (-), CER/[OMIm] $\left[\mathrm{BF}_{4}\right](-\bullet-)$, $\mathrm{CER} /[\mathrm{HEAIm}][\mathrm{Cl}](-\mathbf{-}-)$, and CER/[PHMG][TS] $(-\boldsymbol{\Delta}-)$. 
decrease in $E^{\prime}$ values was observed in the whole glassy region up to $235^{\circ} \mathrm{C}$ (Figure 10a, Table 4), which confirmed the aforementioned conclusion on the formation of a CER matrix with more structural defects compared to all other analogues.

Furthermore, the changes in values of apparent activation energy of $\alpha$ relaxation $\left(\Delta E_{\mathrm{a}}\right)$ calculated for all the samples (Table 4) confirmed the aforementioned observations. First of all, the temperature dependence of frequency, i.e. plots of $\log f v s$. (1000/T) (Figure 11), displayed a steep linearity in the region close to $1 \mathrm{~Hz}$ $(f=1.0-20.0 \mathrm{~Hz})$, which is typical of the $\alpha$ relaxation. For higher $f$ values (at around $10^{3} \mathrm{~Hz}$ and above), this linearity was lost. From these plots, reliable values of $\Delta E_{\mathrm{a}}$ were determined. Indeed, the $E_{\mathrm{a}}$ value can be translated as the amount of energy required to activate the molecular motion and rearrangement of some molecular segments around $T \alpha$ [45, 46]. The $E_{\mathrm{a}}$ value for the CER/[OMIm] $\left[\mathrm{BF}_{4}\right]$ network was very close to that for pure $\operatorname{CER}\left(\Delta E_{\mathrm{a}} \approx 286\right.$ and $292 \mathrm{~kJ} / \mathrm{mol}$, respectively), thus corroborating a similar main transition process related to similar cross-linked structures in both samples because the IL was not chemically embedded into the network. The observed decline in $\Delta E_{\mathrm{a}}$ values for CER/ [HEAIm][Cl] $\left(\Delta E_{\mathrm{a}} \approx 255 \mathrm{~kJ} / \mathrm{mol}\right)$ and CER/ [PHMG] $[\mathrm{TS}]\left(\Delta E_{\mathrm{a}} \approx 196 \mathrm{~kJ} / \mathrm{mol}\right)$ was consistent with the hypothesis of the formation of hybrid CER/IL networks with lower cross-linking density and more mobile kinetic segments between junctions due to

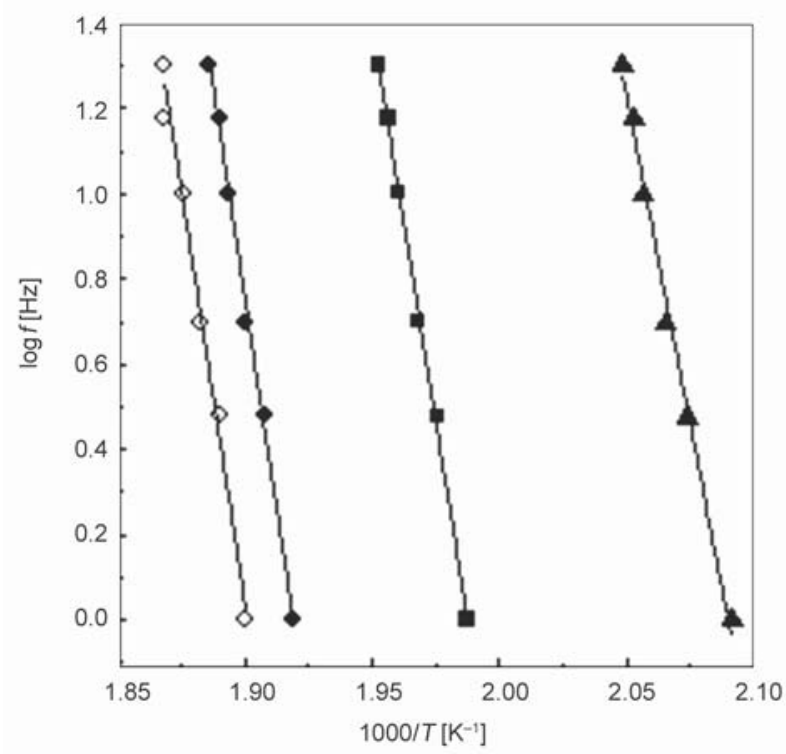

Figure 11. Plot of $\log f v s .1000 / T$ for: CER (-), $\mathrm{CER} /[\mathrm{OMIm}]\left[\mathrm{BF}_{4}\right](-\bullet-)$, $\mathrm{CER} /[\mathrm{HEAIm}][\mathrm{Cl}](-\mathbf{-}-)$, and $\mathrm{CER} /[\mathrm{PHMG}][\mathrm{TS}](-\boldsymbol{\Delta}-)$. the chemical incorporation of the ILs into the CER matrix.

For the CER/[PHMG][TS] network, it is noteworthy that in the $\tan \delta=f(T)$ curve, a second $\tan \delta$ peak was also observed at $284^{\circ} \mathrm{C}$, which could be explained by the post-curing process occurring in the CER matrix, while heating the sample during DMTA measurements above $T_{\alpha}\left(T>240^{\circ} \mathrm{C}\right)$ [47], due to reaction of high mobility residual $-\mathrm{O}-\mathrm{C} \equiv \mathrm{N}$ groups in the hybrid CER/[PHMG][TS] network. Interestingly, a noticeable increase in the $E^{\prime}$ modulus above $T_{\alpha}$ (Figure 10a) for all the networks was also caused by a postcuring effect which occurred upon heating the samples during DMTA measurements, resulting in some increase in the final cross-linking density of CER/IL networks. As it could be seen from Table 4, the postcuring started at different temperatures $\left(T_{\mathrm{pc}(\text { onset })}\right)$ for the different samples: one could assume that the lower the cross-linking density of the cured network, the higher the mobility of the residual $-\mathrm{O}-\mathrm{C} \equiv \mathrm{N}$ groups from CER, and the lower the onset temperature of post-curing.

\section{Conclusions}

This paper thoroughly discussed the kinetic parameters of DCBE polycyclotrimerization in the presence of very small amounts (i.e. $1.0 \mathrm{wt} \%$ ) of ionic liquids with contrasted reactivity, i.e. an aprotic IL ([OMIm] $\left.\left[\mathrm{BF}_{4}\right]\right)$, a protic IL ([HEAIm][Cl]), and a protic polymeric IL ([PHMG][TS]). Further, the relationships between the structure of the densely crosslinked CER/IL networks and their thermal and viscoelastic properties were compared to those associated with neat CER. A strong catalytic effect of all ILs used on DCBE polycyclotrimerization leading to CER network formation was found, and the IL catalytic activity could be ranked as follows: aprotic $[\mathrm{OMIm}]\left[\mathrm{BF}_{4}\right]>$ protic $[$ HEAIm $][\mathrm{Cl}]>$ protic polymeric [PHMG][TS]. Plausible mechanisms for all the DCBE/IL systems were proposed to explain the acceleration effect of the ILs.

One such acceleration effect was significantly higher in the presence of [OMIm] $\left[\mathrm{BF}_{4}\right]$, due to its chemical inertness towards DCBE monomer. In the case of [HEAIm] [Cl] and [PHMG][TS], the chemical grafting of the ILs to CER might occur. The polymer segment mobility and activation energy $\left(E_{\mathrm{a}}\right)$ for $\alpha$ relaxation were studied using DMTA for neat CER and CER/ILs networks. All the samples exhibited a high $T_{\alpha}$ (i.e., $242-262^{\circ} \mathrm{C}$ at $1.0 \mathrm{~Hz}$ ). It was found that the 
physical incorporation of $[\mathrm{OMIm}]\left[\mathrm{BF}_{4}\right]$ into the CER network had no significant influence on $T_{\alpha}$ value compared to that of neat CER. On the contrary, the chemical incorporation of both [HEAIm] $[\mathrm{Cl}]$ and [PHMG][TS] resulted in the significant decrease of $T_{\alpha}$ values for corresponding CER/IL networks caused by the formation of hybrid chemical structures with lower structural regularity than that of neat CER. Nevertheless, TGA results revealed that the catalytic amounts of ILs (i.e., $1 \mathrm{wt} \%$ ) had no major influence on the thermal stability of CER-based networks compared to pure CER.

Accordingly, catalytic amounts of ILs used for the synthesis of CER thermosetting materials do not impair their main thermal characteristics, thus keeping their applicability as suitable matrices for aerospace composites or microelectronic devices.

\section{Acknowledgements}

The authors gratefully acknowledge the National Academy of Sciences of Ukraine (NASU) and the 'Centre National de la Recherche Scientifique' (CNRS) of France for partial financial support (French-Ukrainian LIA project). They are also indebted to Campus France for the Eiffel grant No870769C provided to A. Vashchuk and for the grant N882170D provided to Prof. A. Fainleib for respective stays at the ICMPE.

\section{References}

[1] Hamerton I.: Chemistry and technology of cyanate ester resins. Chapman and Hall, Glasgow (1994).

[2] Fainleib A.: Thermostable polycyanurates: Synthesis, modification, structure and properties. Nova, New York (2010).

[3] Goertzen W. K., Kessler M. R.: Thermal and mechanical evaluation of cyanate ester composites with lowtemperature processability. Composites Part A: Applied Science and Manufacturing, 38, 779-784 (2007). https://doi.org/10.1016/j.compositesa.2006.09.005

[4] Fang T., Shimp D. A.: Polycyanate esters: Science and applications. Progress in Polymer Science, 20, 61-118 (1995). https://doi.org/10.1016/0079-6700(94)E0006-M

[5] Fainleib A., Bardash L., Boiteux G., Grigoryeva O.: Thermosetting cyanate ester resins filled with CNTs. in 'Advances in progressive thermoplastic and thermosetting polymers, perspectives and applications' (eds.: Mamunya Y., Iurzhenko M.), Tehnopress, Iasi, 379-424 (2012).

[6] Grande D., Grigoryeva O., Fainleib A., Gusakova K., Lorthioir C.: Porous thermosets via hydrolytic degradation of poly( $\varepsilon$-caprolactone) fragments in cyanuratebased hybrid networks. European Polymer Journal, 44, 3588-3598 (2008).

https://doi.org/10.1016/j.eurpolymj.2008.08.041
[7] Throckmorton J., Palmese G.: Acceleration of cyanate ester trimerization by dicyanamide RTILs. Polymer, 91, 7-13 (2016).

https://doi.org/10.1016/j.polymer.2016.03.019

[8] Handy S. T.: Room temperature ionic liquids: Different classes and physical properties. Current Organic Chemistry, 9, 959-988 (2005).

https://doi.org/10.2174/1385272054368411

[9] Pârvulescu V. I., Hardacre C.: Catalysis in ionic liquids. Chemical Reviews, 107, 2615-2665 (2007).

https://doi.org/10.1021/cr050948h

[10] Wasserscheid P., Welton T.: Ionic liquids in synthesis. VCH-Wiley, Weinheim (2002).

[11] Zhou J., Cheng L., Wu D.: Ring-opening polymerization of ethylene carbonate using ionic liquids as catalysts. e-Polymers, 11, no. 081 (2011). https://doi.org/10.1515/epoly.2011.11.1.883

[12] Kaoukabi A., Guillen F., Qayouh H., Bouyahya A., Balieu S., Belachemi L., Gouhier G., Lahcini M.: The use of ionic liquids as an organocatalyst for controlled ring-opening polymerization of $\varepsilon$-caprolactone. Industrial Crops and Products, 72, 16-23 (2015).

https://doi.org/10.1016/j.indcrop.2015.02.002

[13] Abdolmaleki A., Mohamadi Z.: Acidic ionic liquids catalyst in homo and graft polymerization of $\varepsilon$-caprolactone. Colloid and Polymer Science, 291, 1999-2005 (2013).

https://doi.org/10.1007/s00396-013-2941-x

[14] Ding S., Radosz M., Shen Y.: Ionic liquid catalyst for biphasic atom transfer radical polymerization of methyl methacrylate. Macromolecules, 38, 5921-5928 (2005). https://doi.org/10.1021/ma050093a

[15] Kanno S.: Challenges for unique application of ionic liquids as a novel initiator of radical polymerization. Molecular Crystals and Liquid Crystals, 603, 3-19 (2014).

https://doi.org/10.1080/15421406.2014.966234

[16] Yang F., Yang J., Zheng K., Stansbury J. W., Nie J.: Electro-induced cationic polymerization of vinyl ethers by using ionic liquid 1-butyl-3-methylimidazolium tetrafluoroborate as initiator. Macromolecular Chemistry and Physics, 216, 380-385 (2015).

https://doi.org/10.1002/macp.201400467

[17] Wu Y-B., Han L., Zhang X-Q., Mao J., Gong L-F., Guo W-L., Gu K., Li S-X.: Cationic polymerization of isobutyl vinyl ether in an imidazole-based ionic liquid: Characteristics and mechanism. Polymer Chemistry, 6, 2560-2568 (2015). https://doi.org/10.1039/C4PY01784F

[18] Livi S., Duchet-Rumeau J., Gérard J-F., Pham T. N.: Polymers and ionic liquids: A successful wedding. Macromolecular Chemistry and Physics, 216, 359-368 (2015). https://doi.org/10.1002/macp.201400425 
[19] Vashchuk A., Fainleib A., Starostenko O., Grande D.: Application of ionic liquids in thermosetting polymers: Epoxy and cyanate ester resins. Express Polymer Letters, 12, 898-917 (2018)

https://doi.org/10.3144/expresspolymlett.2018.77

[20] Fainleib A., Vashchuk A., Starostenko O., Grigoryeva O., Rogalsky S., Nguyen T-T-T., Grande D.: Nanoporous polymer films of cyanate ester resins designed by using ionic liquids as porogens. Nanoscale Research Letters, 12, 126/1-126/9 (2017).

https://doi.org/10.1186/s11671-017-1900-8

[21] Vashchuk A., Rios de Anda A., Starostenko O., Grigoryeva O., Sotta P., Rogalsky S., Smertenko P., Fainleib A., Grande D.: Structure-property relationships in nanocomposites based on cyanate ester resins and 1-heptyl pyridinium tetrafluoroborate ionic liquid. Polymer, 148, 14-26 (2018) https://doi.org/10.1016/j.polymer.2018.06.015

[22] Dzyuba S. V., Bartsch R. A.: Efficient synthesis of 1alkyl(aralkyl)-3-methyl(ethyl)imidazolium halides: Precursors for room temperature ionic liquids. Journal of Heterocyclic Chemistry, 38, 265-268 (2001). https://doi.org/10.1002/jhet.5570380139

[23] Ennis E., Handy T. S.: A facile route to C2-substituted imidazolium ionic liquids. Molecules, 14, 2235-2245 (2009). https://doi.org/10.3390/molecules 14062235

[24] Denk M. K., Ye X.: Alkylation of ethylenethiourea with alcohols: A convenient synthesis of S-alkyl-isothioureas without toxic alkylating agents. Tetrahedron Letters, 46, 7597-7599 (2005).

https://doi.org/10.1016/j.tetlet.2005.08.150

[25] Van Krevelen D. W.: Properties of polymers: Their correlation with chemical structure: Their numerical estimation and prediction from additive group contributions. Elsevier, Amsterdam (2009).

[26] Vogel H.: Das Temperaturabhängigkeit Gesetz der Viskosität von Flüssigkeiten (in German). Physikalische Zeitschrift, 22, 645-646 (1921).

[27] Fulcher G. S.: Analysis of recent measurements of the viscosity of glasses. Journal of the American Ceramic Society, 8, 789-794 (1925).

https://doi.org/10.1111/j.1151-2916.1925.tb18582.x

[28] Tammann G., Hesse W.: Die Abhängigkeit der Viscosität von der Temperatur die unterkühlten Flüssigkeiten (in German). Zeitschrift für anorganische und allgemeine Chemie, 156, 245-257 (1926).

https://doi.org/10.1002/zaac.19261560121

[29] Williams M. L., Landel R. F., Ferry J. D.: The temperature dependence of relaxation mechanisms in amorphous polymers and other glass-forming liquids. Journal of the American Chemical Society, 77, 3701-3707 (1955).

https://doi.org/10.1021/ja01619a008
[30] Li G., Lee-Sullivan P., Thring R. W.: Determination of activation energy for glass transition of an epoxy adhesive using dynamic mechanical analysis. Journal of Thermal Analysis and Calorimetry, 60, 377-390 (2000).

https://doi.org/10.1023/A:1010120921582

[31] Fainleib A., Grigoryeva O., Starostenko O., Vashchuk A., Rogalsky S., Grande D.: Acceleration effect of ionic liquids on polycyclotrimerization of dicyanate esters. Express Polymer Letters, 10, 722-729 (2016). https://doi.org/10.3144/expresspolymlett.2016.66

[32] Bershtein V. A., David L., Egorov V. M., Fainleib A. M., Grigorieva O., Bey I., Yakushev P. N.: Structural/compositional nanoheterogeneity and glass-transition plurality in amorphous polycyanurate-poly(tetramethylene glycol) hybrid networks. Journal of Polymer Science Part B: Polymer Physics, 43, 3261-3272 (2005).

https://doi.org/10.1002/polb.20614

[33] Fainleib A., Grigoryeva O., Hourston D.: Synthesis of inhomogeneous modified polycyanurates by reactive blending of bisphenol A dicyanate ester and polyoxypropylene glycol. Macromolecular Symposia, 164, 429442 (2001).

https://doi.org/10.1002/1521-3900(200102)164:1<429::AIDMASY429>3.0.CO;2-I

[34] Fainleib A., Hourston D., Grigoryeva O., Shantalii T., Sergeeva L.: Structure development in aromatic polycyanurate networks modified with hydroxyl-terminated polyethers. Polymer, 42, 8361-8372 (2001). https://doi.org/10.1016/S0032-3861(01)00333-0

[35] Fainleib A. M., Grigoryeva O. P., Hourston D. J.: Structure-properties relationships for bisphenol A polycyanurate network modified with polyoxytetramethylene glycol. International Journal of Polymeric Materials and Polymeric Biomaterials, 51, 57-75 (2001). https://doi.org/10.1080/00914030213025

[36] Grigat E., Pütter R.: Chemie der Cyansäureester, IV. Umsetzung von Cyansäureestern mit amino- bzw. iminogruppenhaltigen Substanzen (in German). Chemische Berichte, 11, 3027-3035 (1964). https://doi.org/10.1002/cber.19640971110

[37] Bauer J., Bauer M.: Curing of cyanates with primary amines. Macromolecular Chemistry and Physics, 202, 2213-2220 (2001). https://doi.org/10.1002/15213935(20010701)202:11<2213::AID-MACP2213>3.0.CO;2-B

[38] Nyquist R. A., Putzig C. L., Clark T. D.: Infrared study of 1,3-dimethyl-2-imidazolidinone in various solvents. Vibrational Spectroscopy, 12, 81-91 (1996). https://doi.org/10.1016/0924-2031(96)00004-5

[39] Piasek Z., Urbanski T.: The infra-red absorption spectrum and structure of urea. Bulletin de l'Académie Polonaise des Sciences, 10, 113-120 (1962). 
[40] Arshad M. N., Bibi A., Mahmood T., Asiri A. M., Ayub K.: Synthesis, crystal structures and spectroscopic properties of triazine-based hydrazone derivatives; A comparative experimental-theoretical study. Molecules, 20, 5851-5874 (2015).

https://doi.org/10.3390/molecules20045851

[41] Guo R., Sanders D. F., Smith Z. P., Freeman B. D., Paul D. R., McGrath J. E.: Synthesis and characterization of thermally rearranged (TR) polymers: Effect of glass transition temperature of aromatic poly(hydroxyimide) precursors on TR process and gas permeation properties. Journal of Materials Chemistry A, 1, 6063-6072 (2013).

https://doi.org/10.1039/c3ta10261k

[42] Kimura H., Ohtsuka K., Matsumoto A.: Curing reaction of bisphenol-A based benzoxazine with cyanate ester resin and the properties of the cured thermosetting resin. Express Polymer Letters, 5, 1113-1122 (2011). https://doi.org/10.3144/expresspolymlett.2011.108

[43] Korshak V. V., Gribkova P. N., Dmitrenko A. V., Puchin A. G., Pankratov V. A., Vinogradova S. V.: Thermal and thermal-oxidative degradation of polycyanates. Polymer Science U.S.S.R., 16, 15-23 (1974).

https://doi.org/10.1016/0032-3950(74)90111-7
[44] Ramirez M. L., Walters R., Lyon R. E., Savitski E. P.: Thermal decomposition of cyanate ester resins. Polymer Degradation and Stability, 78, 73-82 (2002). https://doi.org/10.1016/S0141-3910(02)00121-0

[45] Ward I. M., Sweeny J.: An introduction to the mechanical properties of solid polymers. Wiley, New York (1993).

[46] Lafia O. A., Imran M. M. A., Abdullah M. K.: Glass transition activation energy, glass-forming ability and thermal stability of $\operatorname{Se}_{90} \operatorname{In}_{10-\mathrm{x}} \operatorname{Sn}_{\mathrm{x}}(\mathrm{x}=2,4,6$ and 8) chalcogenide glasses. Physica B: Condensed Matter, 395, 69-75 (2007). https://doi.org/10.1016/j.physb.2007.02.026

[47] Bershtein V., Fainleib A., Yakushev P.: Polycyanuratebased hybrid networks and nanocomposites: Structureglass transition dynamics-dynamic heterogeneity-properties relationships. in 'Thermostable polycyanurates: Synthesis, modification, structure and properties' Nova Science, New York, 195-246 (2010). 